Article

\title{
Intraspecific Behavioral Variation Mediates Insect Prey Survival via Direct and Indirect Effects
}

\author{
Benjamin J. Toscano ${ }^{1, *}$, James L. L. Lichtenstein ${ }^{2}$ and Raul Costa-Pereira ${ }^{3}$ \\ 1 Department of Biology, Trinity College, Hartford, CT 06106, USA \\ 2 Department of Ecology, Evolution and Marine Biology, University of California Santa Barbara, \\ Santa Barbara, CA 93107, USA; jlllichtenstein@gmail.com \\ 3 Departamento de Biologia Animal, Instituto de Biologia, Universidade Estadual de Campinas, \\ Campinas 13083-862, Brazil; costaper@unicamp.br \\ * Correspondence: benjamin.toscano@trincoll.edu
}

Received: 27 March 2020; Accepted: 12 April 2020; Published: 16 April 2020

\begin{abstract}
Conspecific individuals often exhibit behavioral differences that influence susceptibility to predation. Yet, how such trait differences scale to affect prey population regulation and community structure remains unclear. We used an 8 day field mesocosm experiment to explore the effects of intraspecific prey behavioral trait variation on survival in an herbivorous insect community. We further manipulated spider predator composition to test for top-down context-dependence of behavioral effects. Insect prey behavioral trait variance influenced survival through both direct (i.e., variation among conspecifics) and indirect (i.e., variation among heterospecifics) mechanisms. The behavioral variance of two prey species, Philaenus and Orchelimum, directly reduced their survival, though for Philaenus, this direct negative effect only occurred in the presence of a single spider predator species. In contrast, the survival of Scudderia was enhanced by the behavioral trait variance of the surrounding insect community, an indirect positive effect. Taken together, these results emphasize the importance of accounting for intraspecific variation in community ecology, demonstrating novel pathways by which individual-level behavioral differences scale to alter population and community level patterns.
\end{abstract}

Keywords: animal personality; boldness; food web; herbivorous insects; indirect interaction; intraspecific trait variation; jumping spiders; old field; predator selection; trait-mediated

\section{Introduction}

The importance of prey traits for predatory interactions spans multiple biological scales. For example, predators exert selection on prey populations by preferentially consuming individuals with certain trait values [1-6], but also modify community structure by disproportionally consuming one prey species over another [7]. This latter effect is often ascribed to mean, species-level trait differences [8-10]. Yet these classic empirical approaches overlook the ecological effects of trait variance within prey populations, an outcome of trait differences among individuals that can vary independently from trait means $[11,12]$. While it is unlikely that a single prey individual's traits will modify outcomes at higher organizational scales (but see [13]), population-level prey trait variance could be an important property linking individual traits to the community-level effects of predators. Yet, few studies to date have experimentally explored the effects of prey trait variance on food webs [14-16]. Here, we used a field experiment to examine the effects of insect prey behavioral trait means and behavioral trait variances on the community-structuring effects of their predators (spiders).

Prey trait variance directly impacts prey survival. For example, size-selective predators often have an optimal prey body size for which predation rates are maximized (e.g., a hump-shaped attack 
rate distribution $[17,18])$, and the same likely applies to other types of prey traits [19]. Under such a scenario, increasing variance around the optimal trait mean would increase the prevalence of defended individuals, thereby reducing predation rate [11,20]. Alternatively, if the prey population trait mean deviates from the predator's optimal prey trait value, then increasing variance could increase predation by increasing the prevalence of vulnerable individuals, though this effect would depend on the dominant direction of trait variance [11,20]. These effects of prey trait variance might further depend on predator species identity because predator species often differ in their optimal prey trait values $[8,21]$ as well as the type of selection that they induce (directional, stabilizing, or disruptive) [22].

Trait variance within prey populations could further influence predation rates on other prey species through indirect effects, though the nature of these effects may depend upon the type of phenotypic trait under consideration. If a species' trait variance directly reduces its vulnerability to predation, then this could turn predation pressure towards other prey species within the community. Alternatively, for traits that are relatively labile, such as behavior, the trait variance of interspecific prey could lead to trait changes in a focal species that render it more vulnerable to predation [23,24]. While this latter indirect effect would not occur with prey traits that are fixed over short durations (e.g., body size), this type of indirect effect could be prevalent for traits whose expression is context-dependent, such as behavior [25]. Nevertheless, the majority of studies examine the effects of prey behavioral traits at the individual level (i.e., a natural selection context) [3], while community-level effects of behavioral trait variance remain poorly understood.

Here, we explore how the behavioral trait variances and behavioral trait means of herbivorous insect populations mediate the effects of spider predators on insect survival. We took advantage of naturally occurring boldness (behavioral trait) variation within and across prey populations and manipulated predator species composition to test for context-dependence of behavioral effects. Our study reveals both direct and indirect effects of prey boldness variance, with some effects occurring only under certain spider predator species compositions. These findings demonstrate new pathways by which behavioral trait variation within populations, often overlooked within the field of community ecology [26-28], could scale to regulate community assembly and food web dynamics.

\section{Materials and Methods}

\subsection{Study System and Animal Collection}

We investigated the effects of prey behavior on prey survival using a spider predator-insect prey community system. Our experiment was conducted in a $60 \times 12 \mathrm{~m}$ old-field dominated by ruderal plants (e.g., Solidago spp.) at the Donald S. Wood Field Laboratory (South Shenango, PA, USA). Spiders are important mesopredators within old-field communities, feeding on a variety of herbivorous insects that in turn regulate old-field primary production [29-31]. Preliminary sampling revealed that the jumping spiders Phidippus clarus and Platycryptus undatus were abundant predators at our field site, while four species dominated the herbivorous insect community: meadow froghoppers Philaenus spumarius, bush katydid nymphs from the genus Scudderia, common meadow katydids Orchelimum vulgare, and silver leafhoppers Athysanus argentarius. Given their abundance and thus high likelihood of interacting in the field, we selected these two predator and four prey species for our experiment. Prior to the experiment, we verified that both jumping spider species fed readily upon these insect prey species in one-on-one feeding trials. Spiders and insects were collected by sweep-netting and maintained individually in $50 \mathrm{~mL}$ clear plastic vials before the start of the experiment. Spiders were fed houseflies ad libitum during this 4 day housing period, while insect vials contained a single Solidago canadensis leaf for food and moisture. Individual spiders and insects were used once in the experiment, and survivors were released. 


\subsection{Experimental Design}

We tested the effects of insect prey behavioral trait variances and behavioral trait means on prey survival within replicate field mesocosms. Each $0.36 \mathrm{~m}^{2}$ area mesocosm was stocked with the same insect prey community: 10 Philaenus individuals, 10 Scudderia individuals, 5 Orchelimum individuals, and 5 Athysanus individuals, reflecting the relative abundance of these species at our old-field site. Prior to the placement of insect prey in mesocosms, we assayed the boldness behavior of each individual insect using the same assay (see Prey Behavioral Assay below). Insect prey were then added to mesocosms haphazardly and blindly with respect to their individual behavior (Figure 1) in order to generate naturally occurring behavioral variation within and across prey species' populations. Thus, mesocosm prey communities varied continuously in prey species' mean boldness and boldness variance.

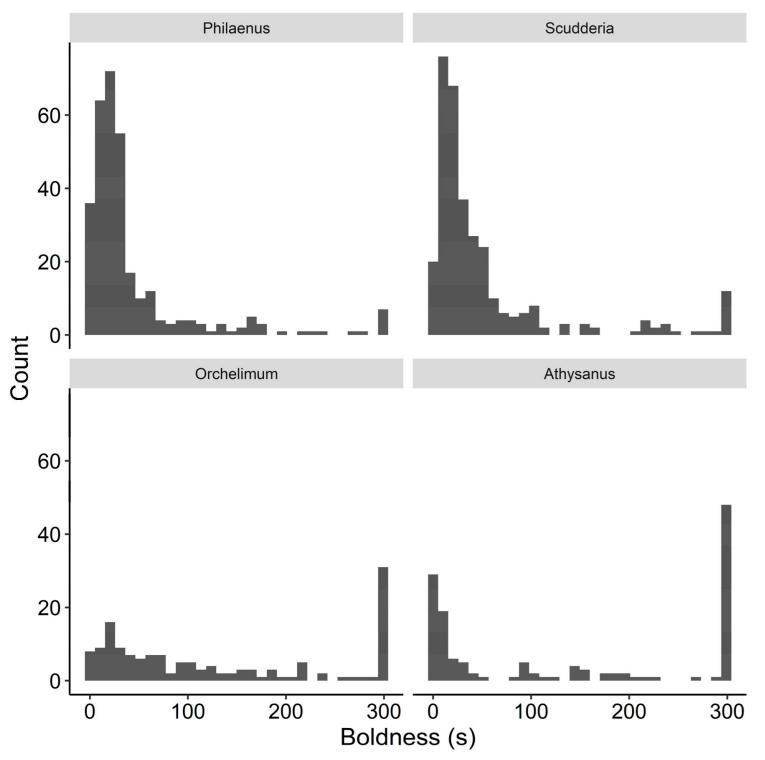

Figure 1. Histograms depicting boldness measurements for insect prey individuals used in the mesocosm experiment. Each mesocosm received 10 Philaenus individuals, 10 Scudderia individuals, 5 Orchelimum individuals, and 5 Athysanus individuals. Prey individuals were added haphazardly and blindly to mesocosms with respect to their individual behavior, generating naturally occurring behavioral variation within and across prey species' populations.

We manipulated spider predator species composition across mesocosms to test whether potential effects of insect prey behavior on prey survival were context dependent (i.e., only occurred under certain predator species compositions). We manipulated spider species composition using three different treatments: two Phidippus spiders per mesocosm ( $\mathrm{n}=10$ mesocosm replicates), two Platycryptus spiders per mesocosm ( $n=13$ mesocosm replicates), or one of each spider species per mesocosm $(n=12$ mesocosm replicates). Given the $0.36 \mathrm{~m}^{2}$ area of our mesocosms, these experimental predator densities were within the range of those observed within our old-field site, as well as those reported for Phidippus within other old-field sites (4-10 spiders per $\left.\mathrm{m}^{2}[29,32]\right)$.

\subsection{Prey Behavioral Assay}

Prior to starting the mesocosm experiment, we measured the behavior of each insect prey individual using the same boldness assay. Boldness, defined as an individual's propensity for risk-taking, can be measured in several ways [33,34]. Following other studies [35-37], we measured boldness as emergence time from a refuge, where individuals that emerge (i.e., enter a potentially dangerous situation) more quickly are considered bolder than individuals that take longer to emerge.

The boldness of each prey individual was measured by placing it, using a small capillary tube, at the bottom of a $50 \mathrm{~mL}$ tube $(11 \mathrm{~cm}$ in length) that opened to a larger arena that insects were unfamiliar 
with. We then recorded the amount of time required for each insect to climb up and out of the tube after it had begun moving within the tube. Assays were terminated if the individual did not move within $300 \mathrm{~s}$. Accordingly, all boldness measurements potentially surpassing $300 \mathrm{~s}$ were assigned the value of $300 \mathrm{~s}$. While we did not assess the repeatability of insect boldness, previous work suggests that boldness is a repeatable trait in both Philaenus and Scudderia [38], as well as for several other herbivorous insect species [39].

\subsection{Mesocosm Design and Assembly}

We used $60(\mathrm{~L}) \times 60(\mathrm{~W}) \times 60 \mathrm{~cm}(\mathrm{H})$ collapsible cages (1450DSV: BioQuip Products, Inc.) as field mesocosms. These cages had a lumite mesh roof and three lumite mesh walls to allow for natural rainfall and humidity variation, while the fourth wall was covered with transparent plastic. Two weeks before mesocosms were set out, we transplanted Solidago canadensis stems to lawns that bordered opposite sides of the old-field. These plants were spaced $2 \mathrm{~m}$ apart, forming a line around the old-field. Immediately before adding the mesocosms, we cut the plants surrounding each transplanted plant to $6 \mathrm{~cm}$ in height. We then placed a mesocosm over each transplanted plant and lined the bottoms of mesocosms with topsoil to prevent organism escape or incursion. The goal of this procedure was to create identical patches of old-field within mesocosms. Solidago plants further provided food and refuge habitat for insect prey during the experiment. All mesocosms were oriented with their plastic side facing north to prevent overheating during sunrise and sunset periods. Before the addition of experimental animals to mesocosms, we conducted several visual scans of all mesocosms and removed naturally occurring insects and spiders.

After this assembly process, we added insect prey to mesocosms and then spiders. Spider predator species composition treatments were assigned randomly to mesocosms, and all treatments were run concurrently. Spiders hid within refuge habitat upon being added to mesocosms, and thus all predation events occurred under natural conditions over the course of the experiment. The boldness behavior of each insect prey individual was known, allowing us to calculate both the mean boldness and boldness coefficient of variation of each prey species' population within each mesocosm (see Analysis). While individual spider behavior was assayed prior to placement in mesocosms, spider behavior did not affect prey survival [40], and spider individuals were randomly assigned to mesocosms to mimic natural predator behavioral variation in the field. After the addition of spiders, mesocosm communities were left undisturbed for eight days, allowing natural trophic dynamics to occur. At the end of this eight-day period, mesocosms were deconstructed, and surviving insects were counted within each mesocosm to measure prey survival.

\subsection{Analysis}

Our analysis compared the effects of insect prey behavioral trait variances and behavioral trait means on prey survival and tested whether these effects depended on spider predator species composition. We built four generalized linear models, with one model for the survival of each insect prey species (Philaenus, Scudderia, Orchelimum, Athysanus). Due to overdispersion, we modeled proportional prey survival response variables using a quasibinomial error distribution within R [41]. Boldness trait variance was calculated as the coefficient of variation $(\mathrm{CV}$; the standard deviation divided by the mean), a standard measure of dispersion. To separate the direct and indirect effects of prey behavior, each model included both the focal species' (i.e., the species whose survival was being modeled) mean boldness and boldness CV (direct effects), as well as the mean boldness and boldness $\mathrm{CV}$ of the rest of the prey community within each mesocosm, excluding the focal species (indirect effects). We further included two-way interactions between each of these four behavioral fixed effects (focal species mean boldness, focal species boldness $\mathrm{CV}$, community mean boldness, community boldness CV) and spider predator species composition (three treatments: Phidippus spiders, Platycryptus spiders, or one individual from each spider species). This approach allowed us to assess (1) direct effects of prey behavior on survival (e.g., the effect of Philaenus behavior on Philaenus survival), 
(2) indirect effects of prey behavior on survival (e.g., the effects of the prey community, minus Philaenus, on Philaenus survival), and (3) the dependence of both direct and indirect effects on spider predator species composition. We tested the significance of fixed effects using likelihood-ratio Chi-square tests ("Anova" function in the "Car" package [42]).

\section{Results}

\subsection{Philaenus Survival}

The population-level behavioral variance of Philaenus influenced its survival (i.e., a direct effect), but this effect was dependent on spider predator species composition. Philaenus survival declined with increasing boldness variance in the presence of Phidippus jumping spiders but not in the other predator treatments, driving a significant interaction between predator treatment and Philaenus boldness variation (Table 1, Figure 2). All other factors, including measurements of mean boldness, failed to predict Philaenus survival (Table 1).

Table 1. ANOVA tables for insect prey survival generalized linear models. Significance of fixed effects, tested using likelihood-ratio Chi-square tests, indicated in bold.

\begin{tabular}{|c|c|c|c|c|}
\hline & Term & $x^{2}$ & d.f. & $P$ \\
\hline \multirow[t]{9}{*}{ Philaenus survival model } & Predator treatment & 0.19 & 2 & 0.91 \\
\hline & Philaenus average boldness & 2.01 & 1 & 0.16 \\
\hline & Philaenus boldness CV & 0.13 & 1 & 0.72 \\
\hline & Community average boldness & 0.84 & 1 & 0.36 \\
\hline & Community boldness CV & 0.92 & 1 & 0.34 \\
\hline & Predator treatment $\times$ Philaenus average boldness & 2.88 & 2 & 0.24 \\
\hline & Predator treatment $\times$ Philaenus boldness CV & 10.55 & 2 & 0.01 \\
\hline & Predator treatment $\times$ Community average boldness & 4.47 & 2 & 0.11 \\
\hline & Predator treatment $\times$ Community boldness CV & 3.39 & 2 & 0.18 \\
\hline \multirow[t]{9}{*}{ Scudderia survival model } & Predator treatment & 0.98 & 2 & 0.61 \\
\hline & Scudderia average boldness & 1.01 & 1 & 0.31 \\
\hline & Scudderia boldness CV & 0.25 & 1 & 0.62 \\
\hline & Community average boldness & 4.38 & 1 & 0.04 \\
\hline & Community boldness CV & 11.28 & 1 & $<0.001$ \\
\hline & Predator treatment $\times$ Scudderia average boldness & 0.80 & 2 & 0.67 \\
\hline & Predator treatment $\times$ Scudderia boldness CV & 0.23 & 2 & 0.89 \\
\hline & Predator treatment $\times$ Community average boldness & 4.99 & 2 & 0.08 \\
\hline & Predator treatment $\times$ Community boldness CV & 4.13 & 2 & 0.13 \\
\hline \multirow[t]{9}{*}{ Orchelimum survival model } & Predator treatment & 3.87 & 2 & 0.14 \\
\hline & Orchelimum average boldness & 0.31 & 1 & 0.58 \\
\hline & Orchelimum boldness CV & 4.86 & 1 & 0.03 \\
\hline & Community average boldness & 0.47 & 1 & 0.49 \\
\hline & Community boldness CV & 1.42 & 1 & 0.23 \\
\hline & Predator treatment $\times$ Orchelimum average boldness & 0.50 & 2 & 0.78 \\
\hline & Predator treatment $\times$ Orchelimum boldness $\mathrm{CV}$ & 0.90 & 2 & 0.64 \\
\hline & Predator treatment $\times$ Community average boldness & 5.41 & 2 & 0.07 \\
\hline & Predator treatment $\times$ Community boldness CV & 2.30 & 2 & 0.32 \\
\hline \multirow[t]{9}{*}{ Athysanus survival model } & Predator treatment & 1.79 & 2 & 0.41 \\
\hline & Athysanus average boldness & 0.41 & 1 & 0.52 \\
\hline & Athysanus boldness CV & 0.00 & 1 & 0.97 \\
\hline & Community average boldness & 0.54 & 1 & 0.46 \\
\hline & Community boldness CV & 0.19 & 1 & 0.66 \\
\hline & Predator treatment $\times$ Athysanus average boldness & 3.10 & 2 & 0.21 \\
\hline & Predator treatment $\times$ Athysanus boldness CV & 2.35 & 2 & 0.31 \\
\hline & Predator treatment $\times$ Community average boldness & 2.30 & 2 & 0.32 \\
\hline & Predator treatment $\times$ Community boldness CV & 0.04 & 2 & 0.98 \\
\hline
\end{tabular}




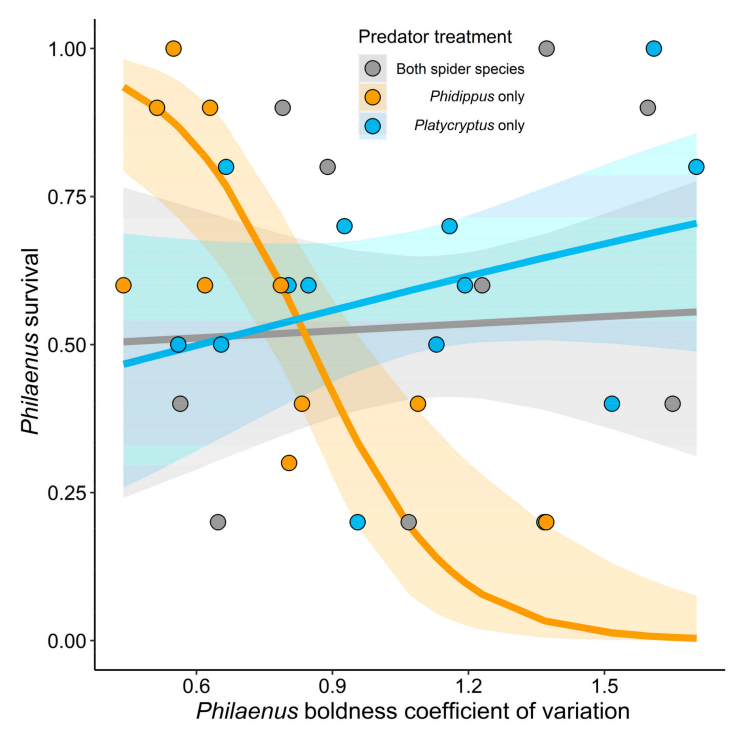

Figure 2. Direct effect of Philaenus prey boldness variance on Philaenus proportional survival in the Phidippus spider predator treatment. Field mesocosms were stocked with 10 Philaenus individuals, and population-level boldness variance was calculated as the coefficient of variation in boldness across these 10 individuals. Shaded areas around marginal effect regression lines represent $84 \%$ confidence intervals generated using the "ggpredict" function in the R package "ggeffects" [43]. Eighty-four percent confidence intervals approximate significant differences at a 95\% confidence level [44].

\subsection{Scudderia Survival}

Scudderia survival increased with increasing boldness variance of the prey community (i.e., an indirect effect), and this effect was consistent across spider predator treatments (Table 1, Figure 3). We also recorded a positive effect of mean community boldness on Scudderia survival, though this effect was relatively weak (Table 1). Scudderia population-level behavioral metrics did not influence its survival (i.e., no evidence for direct effects; Table 1).

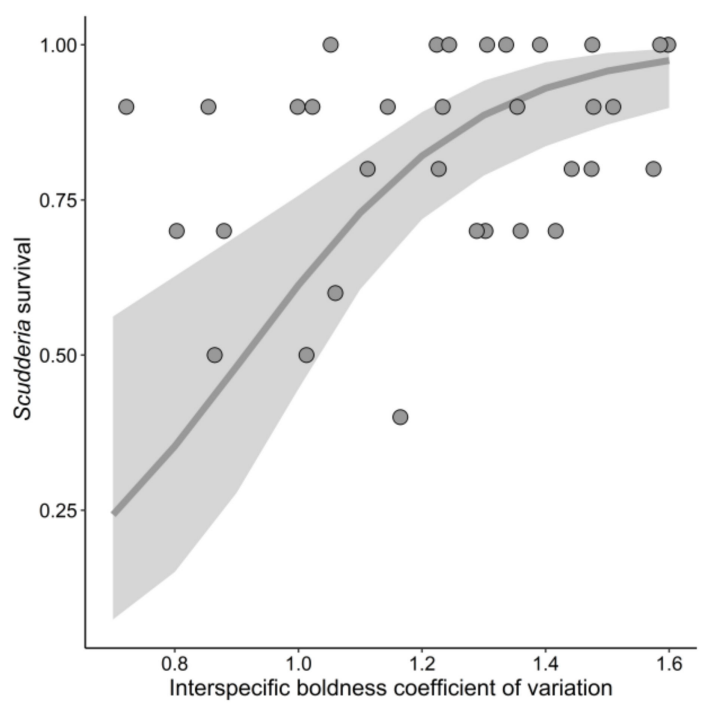

Figure 3. Indirect effect of prey community boldness variance on Scudderia proportional survival across all spider predator treatments. Field mesocosms were stocked with 10 Scudderia individuals, and community boldness variance was calculated as the coefficient of variation in boldness all prey species (Philaenus, Orchelimum, Athysanus) minus the focal species Scudderia. Shaded areas around marginal effect regression line represent $84 \%$ confidence intervals generated using the "ggpredict" function in the R package "ggeffects" [43]. 


\subsection{Orchelimum Survival}

Similar to Philaenus, we recorded a negative direct effect of Orchelimum population-level behavioral variance on its survival (Figure 4, Table 1), though this effect was consistent across spider predator treatments (Table 1). All other factors, including measurements of mean boldness, failed to predict Orchelimum survival (Table 1).

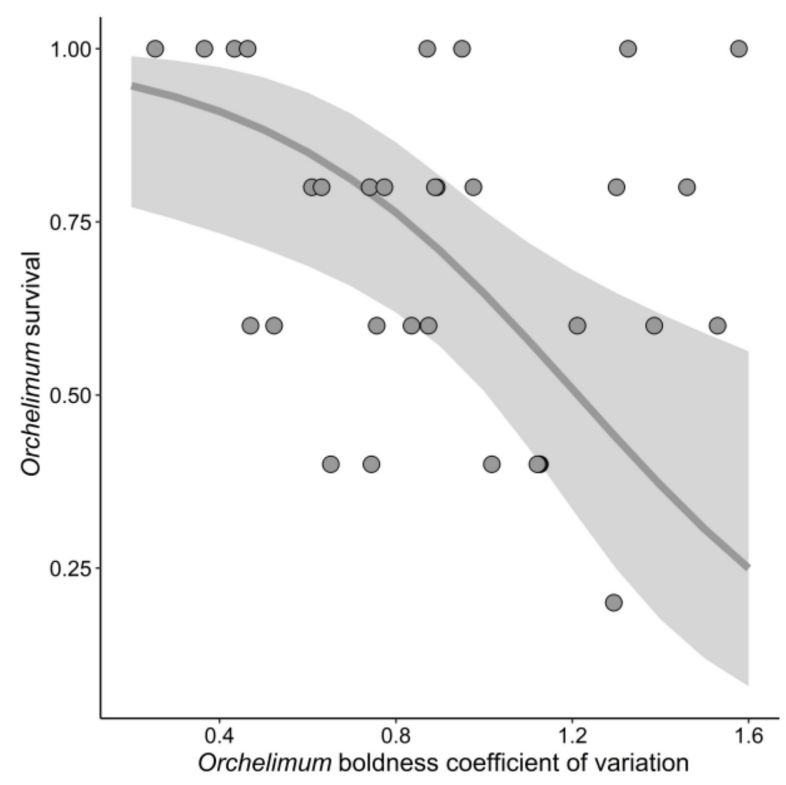

Figure 4. Direct effect of Orchelimum prey boldness variance on Orchelimum proportional survival across all spider predator treatments. Field mesocosms were stocked with 5 Orchelimum individuals, and population-level boldness variance was calculated as the coefficient of variation in boldness across these 5 individuals. Shaded areas around marginal effect regression line represent $84 \%$ confidence intervals generated using the "ggpredict" function in the R package "ggeffects" [43].

\subsection{Athysanus survival}

None of the model factors were significant predictors of Athysanus survival (Table 1).

\section{Discussion}

While myriad studies have established the importance of prey traits for predator-prey interactions $[3,17,19]$, these studies are typically focused at either the individual level within a natural selection context [3] or at the community level within a species selection context [45]. Such traditional approaches overlook the ecological effects of population- or group-level trait variance [11], a potential key property linking the traits of individuals to communities. Here, using a field experiment, we showed that prey behavioral trait variances have decisive effects on herbivorous insect survival as mediated by spider predators, while behavioral trait means offer relatively less explanatory power. Importantly, such effects of prey behavioral trait variance on survival arose via both direct and indirect mechanisms. Behaviorally variant populations of both Philaenus and Orchelimum experienced reduced survival compared to behaviorally homogeneous populations (i.e., direct negative effects). Yet for Philaenus, this direct negative effect was only manifested in the presence of Phidippus spiders, a context-dependent effect of behavioral trait variance. We further detected an indirect effect whereby the aggregate behavioral trait variance of the surrounding prey community, Philaenus, Orchelimum, and Athysanus, improved the survival of Scudderia. In total, these findings revealed new and intricate pathways by which prey behavioral traits scale to shape prey community structure via a shared predator. 


\subsection{Differences across Prey Species}

The nature of direct and indirect interactions within our study system was largely prey species dependent. While Philaenus and Orchelimum boldness trait variance reduced their probability of survival, we found no evidence for direct effects in the other two prey species. Furthermore, Scudderia was the only prey species whose survival was influenced by an indirect effect. This suggests that the effects of behavioral trait variance are not universal but rather dependent on prey species' functional traits.

Direct negative effects of Philaenus and Orchelimum boldness variance on survival could be due to spiders' increased capture efficiency of behaviorally extreme prey individuals (e.g., particularly bold or shy individuals) whose availability increases in more behaviorally variant groups. Previous work by Lichtenstein et al. (2017) confirmed this direct negative effect of Philaenus behavioral variance on Philaenus survival, though this study estimated behavioral hypervolumes from three Philaenus behavioral traits: activity level, boldness, and space use [38]. If these effects of behavioral variance persist in the field, then spiders could drive stabilizing selection on Philaenus and Orchelimum boldness via the improved survival of behaviorally intermediate individuals [46]. More specifically, Philaenus experienced this direct negative effect in the presence of Phidippus spiders but not Platycryptus spiders or the treatment in which both spider species were included. Such a context-dependent direct negative effect may stem from the unique predator avoidance (i.e., escape) abilities of Philaenus froghoppers, who are better jumpers for their size than fleas [47]. We suggest it is possible that Phidippus was the only predator able to capture Philaenus individuals at either end of the boldness spectrum.

Improved Scudderia survival in the presence of behaviorally variant insect prey communities could result from Scudderia behavioral modifications over the course of the experiment. While we assayed individual insect boldness a few days before running our experiment, this does not preclude behavioral changes during the experiment. As such, it is possible that the surrounding prey community modified Scudderia behavior in such a way that enhanced their survival. Clearly, additional work is required to probe the underlying behavioral mechanisms behind these interactions and assess their generality. We believe that a better understanding of the role of functional traits in regulating behaviorally mediated interactions will increase predictability across systems.

\subsection{Indirect Effect Mediated by a Shared Predator}

Our study sheds new light on interactions between prey species mediated by a shared predator, a major class of indirect effects. The most well-studied of these interactions is apparent competition, which in its most basic form describes the scenario in which prey species indirectly reduce one another's densities via the positive numerical response of a shared predator [48,49]. Other work shows that agonistic interactions between prey can similarly increase predation rates, even in the absence of any predator numerical response [24]. Our study describes a related indirect effect, apparent commensalism, where the behavioral variance of the surrounding prey community increases the survival of Scudderia in the presence of a shared predator.

\subsection{Conclusion and Future Directions}

Individual-level trait variation is ubiquitous within natural populations, but ecologists are just beginning to appreciate the full extent of its effects on community-level processes [26,27,50]. Our study demonstrates the importance of behavioral trait variance in regulating insect survival, effectively scaling the effects of individual traits to the community level. In contrast, we found the effects of behavioral trait means to be relatively weak in magnitude (i.e., having relatively less predictive power). Our findings further suggest prey species specificity in the effects of trait variance, adding a new level of complexity to our understanding of predator-prey systems. While such complexity could be expected to diminish the predictability of predator-prey dynamics, we contend that such idiosyncratic responses might help explain the striking variation in community structure observed along natural gradients. Our study suggests that the magnitude of direct and indirect effects could change substantially across 
ecological gradients (e.g., trait variance within species, the presence of specific predators), thereby supporting heterogeneous landscapes of species interactions [51]. Though underexplored, we expect that future empirical and theoretical explorations of such gradient-dependence will provide new insight into the structure and functioning of natural communities.

Author Contributions: Conceptualization, B.J.T., R.C.-P., and J.L.L.L.; methodology, J.L.L.L.; formal analysis, B.J.T. and R.C.-P.; investigation, J.L.L.L.; writing-original draft preparation, B.J.T.; writing-review and editing, B.J.T., R.C.-P., and J.L.L.L. All authors have read and agreed to the published version of the manuscript.

Funding: This research was funded by the Pape Foundation and the McKinley Foundation of the University of Pittsburgh.

Acknowledgments: We wish to thank H. Rice for help in the field and the Editors of this Special Issue for inviting our submission. We are further grateful to the Pymatuning Laboratory of Ecology for hosting field work.

Conflicts of Interest: The authors declare no conflict of interest.

\section{References}

1. Reed, W.L.; Janzen, F.J. Natural selection by avian predators on size and colour of a freshwater snail (Pomacea flagellata). Biol. J. Linn. Soc. 1999, 67, 331-342. [CrossRef]

2. Strobbe, F.; McPeek, M.A.; Block, M.D.; Stoks, R. Survival selection imposed by predation on a physiological trait underlying escape speed. Funct. Ecol. 2010, 24, 1306-1312. [CrossRef]

3. Moiron, M.; Laskowski, K.L.; Niemelä, P.T. Individual differences in behaviour explain variation in survival: A meta-analysis. Ecol. Lett. 2020, 23, 399-408. [CrossRef] [PubMed]

4. Holmes, T.H.; McCormick, M.I. Influence of prey body characteristics and performance on predator selection. Oecologia 2009, 159, 401-413. [CrossRef]

5. Keiser, C.N.; Ingley, S.J.; Toscano, B.J.; Scharf, I.; Pruitt, J.N. Habitat complexity dampens selection on prey activity level. Ethology 2018, 124, 25-32. [CrossRef]

6. Pretorius, J.D.; Lichtenstein, J.L.L.; Eliason, E.J.; Stier, A.C.; Pruitt, J.N. Predator-induced selection on urchin activity level depends on urchin body size. Ethology 2019, 125, 716-723. [CrossRef]

7. Paine, R.T. Food Web Complexity and Species Diversity. Am. Nat. 1966, 100, 65-75. [CrossRef]

8. Huey, R.B.; Pianka, E.R. Ecological consequences of foraging mode. Ecology 1981, 62, 991-999. [CrossRef]

9. Ritger, A.L.; Fountain, C.T.; Bourne, K.; Martín-Fernández, J.A.; Pierotti, M.E.R. Diet choice in a generalist predator, the invasive lionfish (Pterois volitans/miles). J. Exp. Mar. Biol. Ecol. 2020, 524, 151311. [CrossRef]

10. Shultz, S.; Noë, R.; McGraw, W.S.; Dunbar, R.I.M. A community-level evaluation of the impact of prey behavioural and ecological characteristics on predator diet composition. Proc. R. Soc. Lond. B Biol. Sci. 2004, 271, 725-732. [CrossRef]

11. Dibble, C.J.; Rudolf, V.H.W. Phenotype-environment matching predicts both positive and negative effects of intraspecific variation. Am. Nat. 2019, 194, 47-58. [CrossRef]

12. Lichtenstein, J.L.L.; Daniel, K.A.; Wong, J.B.; Wright, C.M.; Doering, G.N.; Costa-Pereira, R.; Pruitt, J.N. Habitat structure changes the relationships between predator behavior, prey behavior, and prey survival rates. Oecologia 2019, 190, 297-308. [CrossRef] [PubMed]

13. Modlmeier, A.P.; Keiser, C.N.; Watters, J.V.; Sih, A.; Pruitt, J.N. The keystone individual concept: An ecological and evolutionary overview. Anim. Behav. 2014, 89, 53-62. [CrossRef]

14. Start, D. Individual and population differences shape species interactions and natural selection. Am. Nat. 2019, 194, 183-193. [CrossRef] [PubMed]

15. McGhee, K.E.; Pintor, L.M.; Bell, A.M. Reciprocal behavioral plasticity and behavioral types during predator-prey interactions. Am. Nat. 2013, 182, 704-717. [CrossRef]

16. Palkovacs, E.P.; Post, D.M. Eco-evolutionary interactions between predators and prey: Can predator-induced changes to prey communities feed back to shape predator foraging traits? Evol. Ecol. Res. 2008, 10, 699-720.

17. Brose, U. Body-mass constraints on foraging behaviour determine population and food-web dynamics. Funct. Ecol. 2010, 24, 28-34. [CrossRef]

18. Costa-Pereira, R.; Araújo, M.S.; Olivier, R.; Da, S.; Souza, F.L.; Rudolf, V.H.W. Prey limitation drives variation in allometric scaling of predator-prey interactions. Am. Nat. 2018, 192, E139-E149. [CrossRef] 
19. Boukal, D. Trait-and size-based descriptions of trophic links in freshwater food webs: Current status and perspectives. J. Limnol. 2014, 73, 171-185. [CrossRef]

20. Gibert, J.P.; Brassil, C.E. Individual phenotypic variation reduces interaction strengths in a consumer-resource system. Ecol. Evol. 2014, 4, 3703-3713. [CrossRef]

21. Brousseau, P.-M.; Gravel, D.; Handa, I.T. Trait matching and phylogeny as predictors of predator-prey interactions involving ground beetles. Funct. Ecol. 2018, 32, 192-202. [CrossRef]

22. Kingsolver, J.G.; Pfennig, D.W. Patterns and power of phenotypic selection in nature. BioScience 2007, 57, 561-572. [CrossRef]

23. Huang, C.; Sih, A. Experimental studies on behaviorally mediated, indirect interactions through a shared predator. Ecology 1990, 71, 1515-1522. [CrossRef]

24. Toscano, B.J.; Fodrie, F.J.; Madsen, S.L.; Powers, S.P. Multiple prey effects: Agonistic behaviors between prey species enhances consumption by their shared predator. J. Exp. Mar. Biol. Ecol. 2010, 385, 59-65. [CrossRef]

25. Dingemanse, N.J.; Kazem, A.J.N.; Réale, D.; Wright, J. Behavioural reaction norms: Animal personality meets individual plasticity. Trends Ecol. Evol. 2010, 25, 81-89. [CrossRef]

26. Bolnick, D.I.; Amarasekare, P.; Araújo, M.S.; Bürger, R.; Levine, J.M.; Novak, M.; Rudolf, V.H.W.; Schreiber, S.J.; Urban, M.C.; Vasseur, D.A. Why intraspecific trait variation matters in community ecology. Trends Ecol. Evol. 2011, 26, 183-192. [CrossRef]

27. Toscano, B.J.; Gownaris, N.J.; Heerhartz, S.M.; Monaco, C.J. Personality, foraging behavior and specialization: Integrating behavioral and food web ecology at the individual level. Oecologia 2016, 182, 55-69. [CrossRef]

28. Modlmeier, A.P.; Keiser, C.N.; Wright, C.M.; Lichtenstein, J.L.; Pruitt, J.N. Integrating animal personality into insect population and community ecology. Curr. Opin. Insect Sci. 2015, 9, 77-85. [CrossRef]

29. Hoefler, C.D.; Chen, A.; Jakob, E.M. The potential of a jumping spider, Phidippus clarus, as a biocontrol agent. J. Econ. Entomol. 2006, 99, 432-436. [CrossRef]

30. Beckerman, A.P.; Uriarte, M.; Schmitz, O.J. Experimental evidence for a behavior-mediated trophic cascade in a terrestrial food chain. Proc. Natl. Acad. Sci. USA 1997, 94, 10735-10738. [CrossRef]

31. Chase, J.M. Abiotic controls of trophic cascades in a simple grassland food chain. Oikos 1996, 77, 495-506. [CrossRef]

32. Rothley, K.D.; Schmitz, O.J.; Cohon, J.L. Foraging to balance conflicting demands: Novel insights from grasshoppers under predation risk. Behav. Ecol. 1997, 8, 551-559. [CrossRef]

33. Réale, D.; Reader, S.M.; Sol, D.; McDougall, P.T.; Dingemanse, N.J. Integrating animal temperament within ecology and evolution. Biol. Rev. 2007, 82, 291-318. [CrossRef] [PubMed]

34. Beckmann, C.; Biro, P.A. On the validity of a single (boldness) assay in personality research. Ethology 2013, 119, 937-947. [CrossRef]

35. Brown, C.; Braithwaite, V.A. Size matters: A test of boldness in eight populations of the poeciliid Brachyraphis episcopi. Anim. Behav. 2004, 68, 1325-1329. [CrossRef]

36. Hedrick, A.V.; Kortet, R. Sex differences in the repeatability of boldness over metamorphosis. Behav. Ecol. Sociobiol. 2012, 66, 407-412. [CrossRef]

37. Harris, S.; Ramnarine, I.W.; Smith, H.G.; Pettersson, L.B. Picking personalities apart: Estimating the influence of predation, sex and body size on boldness in the guppy Poecilia reticulata. Oikos 2010, 119, 1711-1718. [CrossRef]

38. Lichtenstein, J.L.L.; Wright, C.M.; McEwen, B.; Pinter-Wollman, N.; Pruitt, J.N. The multidimensional behavioural hypervolumes of two interacting species predict their space use and survival. Anim. Behav. 2017, 132, 129-136. [CrossRef]

39. Bell, A.M.; Hankison, S.J.; Laskowski, K.L. The repeatability of behaviour: A meta-analysis. Anim. Behav. 2009, 77, 771-783. [CrossRef]

40. Lichtenstein, J.L.L.; Rice, H.K.; Pruitt, J.N. Personality variation in two predator species does not impact prey species survival or plant damage in staged mesocosms. Behav. Ecol. Sociobiol. 2018, 72, 70. [CrossRef]

41. R Core Team. R: A Language and Environment for Statistical Computing; R Foundation for Statistical Computing: Vienna, Austria, 2019.

42. Fox, J.; Weisberg, S.; Adler, D.; Bates, D.; Baud-Bovy, G.; Ellison, S.; Firth, D.; Friendly, M.; Gorjanc, G.; Graves, S. Package 'car.' Vienna R Found. Stat. Comput. 2012.

43. Lüdecke, D. ggeffects: Tidy data frames of marginal effects from regression models. J. Open Source Softw. 2018, 3, 772. [CrossRef] 
44. MacGregor-Fors, I.; Payton, M.E. Contrasting diversity values: Statistical inferences based on overlapping confidence intervals. PLoS ONE 2013, 8, e56794. [CrossRef] [PubMed]

45. Vellend, M. The Theory of Ecological Communities; Princeton University Press: Princeton, NJ, USA, 2016.

46. Adriaensen, F.; Dhondt, A.A.; Dongen, S.V.; Lens, L.; Matthysen, E. Stabilizing selection on blue tit fledgling mass in the presence of sparrowhawks. Proc. R. Soc. Lond. B Biol. Sci. 1998, 265, 1011-1016. [CrossRef]

47. Burrows, M. Froghopper insects leap to new heights. Nature 2003, 424, 509-509. [CrossRef] [PubMed]

48. Bonsall, M.B.; Hassell, M.P. Apparent competition structures ecological assemblages. Nature 1997, 388, 371-373. [CrossRef]

49. Holt, R.D.; Kotler, B.P. Short-term apparent competition. Am. Nat. 1987, 130, 412-430. [CrossRef]

50. Dall, S.R.X.; Bell, A.M.; Bolnick, D.I.; Ratnieks, F.L.W. An evolutionary ecology of individual differences. Ecol. Lett. 2012, 15, 1189-1198. [CrossRef]

51. Costa-Pereira, R.; Rudolf, V.H.W.; Souza, F.L.; Araújo, M.S. Drivers of individual niche variation in coexisting species. J. Anim. Ecol. 2018, 87, 1452-1464. [CrossRef]

(C) 2020 by the authors. Licensee MDPI, Basel, Switzerland. This article is an open access article distributed under the terms and conditions of the Creative Commons Attribution (CC BY) license (http://creativecommons.org/licenses/by/4.0/). 